\title{
Confirmatory Influence of Trust in E-commerce: A Data Collection Bias and Suggestion
}

\author{
Obi Ogbanufe \\ Oklahoma State University \\ Obi.Ogbanufe@okstate.edu
}

\author{
Dan J. Kim \\ University of North Texas \\ dan.kim@unt.edu
}

\begin{abstract}
In most trust studies, its dimensions and antecedents have been studied with an overwhelming evidence showing trust as a critical determinant of behavioral intention to purchase. The focus has been on confirming the investigation of trust as a determinant on successful only purchases. This paper explores the importance of investigating the impact of trust on intention to purchase from both successful and unsuccessful purchase cases in order to provide a more balanced view of the critical role of trust in ecommerce transaction decisions. It also aims to contribute to the rigor of information systems (IS) research practices related to data collection methods. Our findings provide important insights into the varying effect of trust on intention, which becomes apparent when data collection methods allow for the testing of cases of successful and non-successful purchases.
\end{abstract}

\section{Introduction}

The outlook for electronic commerce (e-commerce) has significantly improved in part because of the advent of the combination of e-commerce, mobile commerce and the authentication that enables its seamless integration. Since the commercialization of the Internet in 1995, there has been numerous IS studies on the determinants of intention to purchase through e-commerce [e.g.; 2,4,7,20,32,33,40,41,42,43]. In these e-commerce and trust studies, trust, its dimensions, and antecedents have been studied with an overwhelming evidence showing that trust is a critical determinant of behavioral intention to purchase. However, the focus of most empirical trust studies has been on the confirmatory aspect of the investigation which only uses successful purchase cases (e.g., successful purchase experiences or more inclined to purchase cases). Given that success only purchases represent only a fraction of all consumer online transaction behavior, studies using only this type of data paint an incomplete picture. Therefore, we argue that this aspect of empirical investigation has a bias. In order to provide an unbiased view, it is important to investigate and compare the results of the impact of trust on intention to purchase from both successful and unsuccessful cases at the same time. This approach gives a more balanced view of the critical role of trust in e-commerce transaction decisions.

Surprisingly, there are very limited studies investigating the role of trust from a balanced view and comparing the impact of trust from both cases at the same time. It has been argued that while much research on trust has examined how trust affects several behavioral intentions, it has largely ignored the conditions under which trust has a varying effect on behavioral intentions [11]. This type of examination is further described as one where we assume that trust always has an unconditional positive effect on behavioral outcomes, and has been referred to as "an oversimplification of the context in which trust operates" $[11: 280]$. Thus, this research responds to the call to further examine the effect of trust on behavioral intentions, by considering an unbiased view of the impact of trust in e-commerce. We suggest that a balanced approach should be applied in order to adequately measure the influence of trust. In other words, when testing the effect of trust on behavioral intentions/actual behaviors, a measurement of trust should be applied to different conditions; where trust is shown to have positively and "successfully" impacted behavioral intention to purchase, as well as where trust positively but "unsuccessfully" impacts intention. Measuring and testing both scenarios eliminates potential biases in data collection and instrument measurement, which today is geared only towards the confirmation of intended behavior, thus ignoring other behaviors in the system.

There is a tendency for researchers to prefer their favored hypotheses with tenacity and confidence; this 
tendency is referred to as perseverance of beliefs or hypothesis preservation [22]. It is arguably the tendency to test an existing belief and to search for evidence which confirms that belief [18]. This impacts on the decision that researchers make in data collection and testing. The result of which may be a systematic bias in learning the effects of a particular concept or phenomenon. For example, a researcher that repeatedly faces the same set of concept/construct testing options may retain the belief that those options are optimal, without regard for other avenues to test or interpret the concept. Furthermore, Jones and Sugden [18:59] notes that ... "there is a bias if, relative to norms of valid reasoning, excessive effort is devoted to the search for confirming evidence." Therefore, we propose a balanced data collection method that helps uncover the varying effects of trust in different situations. We believe that as strong a determinant as studies have confirmed it to be, it is important to understand other scenarios in e-commerce where trust is ineffective, or not as strong a determinant.

Popper [37:36] notes that "every good scientific theory is a prohibition ... it forbids certain things to happen, and every genuine test of a theory is an attempt to falsify it. Confirming evidence should not count except when it is the result of a genuine test of theory." This supports the argument of this study in the sense that we are applying rigor in order to identify and rule out conditions under which trust does not impact purchase behavior. In other words, in order to test a theory, one has to look for possible violations of it [18]. For example, in the testing of drugs, if all the testing conditions are ones that successfully and positively confirm that the drug works, with no possible test of conditions under which the drug is ineffective, individuals will be justified to be suspicious of such a drug. Meaning that more testing needs to be performed.

Therefore, this study seeks to answer the research question: "under what condition will trust in ecommerce not affect intention to purchase?" The goal of this study is to present balanced scenarios and empirically test where trust is shown to have positively and "successfully" impacted behavioral intention to purchase, as well as where trust positively but "unsuccessfully" impacts intention, and to present evidence showing both sides. This strategy is in keeping with the notion of pressing the limits a little further, a well-known scientific strategy for understanding and exploring behavior at the boundaries [21]. It is testing whether the same trust factors that account for intention to perform online purchases (normal performance) can account for other behaviors (non-normal performance) [21].

\section{Theoretical Background}

This paper reviews previous empirical studies of trust in online environments. A search of literature in information systems research, management information systems quarterly, decision support systems, journal of management information systems revealed several studies where "trust" was indicated on the research title. The criteria for selecting the study are that it must be empirical in nature, have "intention", "actual behavior" or "willingness to perform behavior" as a dependent variable, and it must also be based on survey methodology. On the basis of this review, we identify only one study [20] that tested the impact of trust using both successful and unsuccessful case data with equal diligence. The rest of the studies tested the effect of trust using only successful case data. We identify this as a confirmatory bias in the investigation and testing of the effects of focal constructs such as trust in e-commerce in this study. To minimize the bias, this study suggests a strategy to collect a balanced data for testing the critical role of focal constructs (i.e., trust in ecommerce in this study).

\subsection{Trust and its Consequents}

There is no disputing the many studies that have indicated that high levels of trust are associated with purchase intention [12], or the myriad studies that have explored and confirmed the relationship between trust and e-commerce purchase intention, especially in situations that involve elements of risks $[12,13,26]$. Indeed, as a main focal construct in e-commerce, trust and its consequents have been studied. However, the notion that high trust seems to be the only identified factor determining purchase intention forms the basis of the current study. This notion limits the data collection to only collect data that confirms the hypothesis. Thus, we suggest a balanced data collection approach to validate the critical role of trust. Figure 1 depicts the consideration for both cases - i.e., online consumers who are less inclined to purchase (case 1) and more inclined to purchase (case 2). An approach that reduces the confirmatory bias and provides a more balanced view of the critical role of trust in e-commerce transaction decisions. 


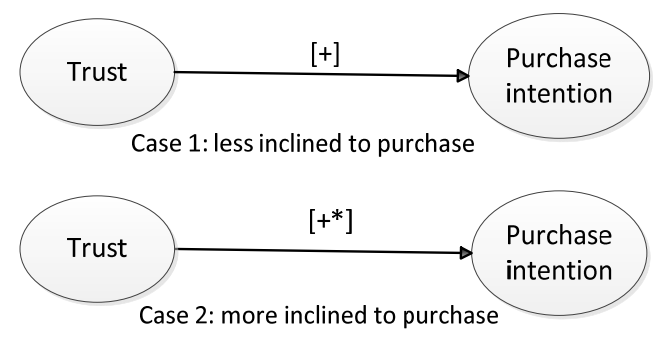

[+] Positive but possibly insignificant relationship [+*] Positive and significant relationship

Figure 1: High level depiction of study focus

E-commerce trust studies that should test the consequents of trust using balanced data collection strategies (i.e. unsuccessful and successful cases) is sparse. See Appendix A. By analogy, research geared only towards confirmation of successful cases could be viewed like driving, where the only movement directions available and performed are forward, right and left; with no opportunity for reverse movements. Just as reverse/backward driving movement provides a Consistent with theoretical arguments underlying trust and intention, we anticipate direct impact of high levels of trust on perceived risk (RISK), perceived benefit (BENEFIT), and willingness to purchase (WP). We also anticipate that low levels of trust will impact WP in a manner different from high trust. Following the study by Kim et al. [20], some control variables (disposition to trust, familiarity and dollar value) are included in this study to ensure consistency in validating their effects on the major constructs.

\section{Research Model and Hypotheses}

In this study, we propose an approach to testing the effect of trust in e-commerce. First, we acknowledge the importance of the call for further examination of the effect of trust on behavioral intentions and the limitation of current testing methods [3,11]. Second, we focus on exerting equal diligence in testing our hypotheses for (1) behavioral evidence to confirm the hypothesis [39], and (2) evidence that exposes other conditions that may vary the effect of trust. Thus, pressing the limits for understanding and exploring behavior at the boundaries [21].

In order to validate the proposed approach to testing the effect of trust, we adapt the pre-purchase phase model that Kim et al. [20] empirically studied on the effect of trust and satisfaction in e-commerce and show the effect of trust on purchase intention as a consequent of trust. Figure 2 presents the research model that we apply the proposed approach. Drawing on valence theory [16] as the theoretical background of the model, we create a context-specific representation of simultaneous evaluation of risk and benefit [35]. In developing a more systematic account of the conditions under which trust has a varying effect, we focus on behavioral intention as on outcome. Hence, the portion of the Kim et al. [20] model chosen is the part that depicts the focal construct (i.e., trust) affecting behavioral intention.

As highlighted before, this research focuses on identifying the successful and unsuccessful outcomes of the effect of trust on behavior intention, the conditions for each outcome, and the effect of other variables on the outcomes of both successful and unsuccessful models. This approach thus builds on Kim's, formalizing why a balanced data collection and testing of both successful and unsuccessful outcomes matter in understanding the effects of trust on ecommerce.

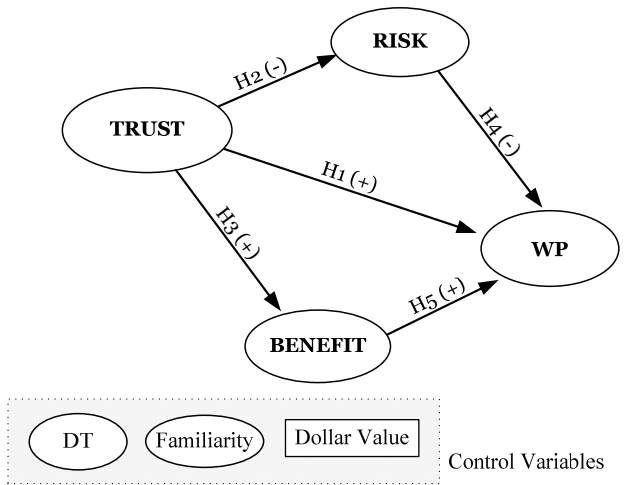

Figure 2: Research Model

It should be noted that the focus of this study is less about the validation and testing of the hypotheses (as this have been done in several trust studies), and more about testing the varying effect on trust under two data collection conditions. One condition is when individuals are more inclined to purchase, and the other is when another group of individuals are less inclined to purchase.

\subsection{Hypotheses}

Trust reduces the individual's vulnerability, such that a high level of trust tends to increase the likelihood of intention to transact with another entity. Conversely, we posit that a low level of trust tends to decrease the likelihood of purchase intention. For example, when an individual exhibits a low inclination towards a website, $\mathrm{s} / \mathrm{he}$ is less likely to purchase from that website. When an individual is presented with two different websites, where the individual has developed beliefs about one of the website's ability, benevolence, and integrity [28]. The individual is more likely to purchase from 
this website than from the other where trusting beliefs have not been established. There is considerable support in literature for effect of trust on intention (i.e. willingness to purchase). Willingness to purchase is defined as the extent to which an individual intends to make a purchase from a website. Trust has been utilized to explain and predict satisfaction [20], perceived usefulness and intention [13,14]. Consistent with these studies, we hypothesize that:

H1: There will be a strong positive effect of trust (TRUST) on a consumer's WP when there is high level of consumer trust

Perceived risk has been defined as an individual's expectation of an unwanted outcome during or after an online transaction [15]. As a result of its inherent properties (anonymity, dispersed geography etc.), internet transactions present a level of risk to individuals. This perceived risk has been shown to be reduced when trust is introduced. Following, many studies that have tested the relationship between trust and perceived risk in online transactions [11,19,31], we expect that trust reduces an individual's perception of risk. Therefore, we hypothesize that:

H2. Perceived risk (RISK) is negatively related to a consumer's trust (TRUST)

Following the preceding hypothesis that tests whether trust reduces the perception of risk, we posit that the direct effect of risk perception on willingness to purchase is negative. In other words, when an individual is confronted with the notion of risks in an online transaction, $\mathrm{s} / \mathrm{he}$ is less likely to transact online with the website, especially when the transaction is a first-time purchase from that website. Many studies support the relationship between risk perception and intention $[31,34]$. Therefore, we hypothesize that:

H3. Perceived risk (RISK) is negatively related to a consumer's WP

Perceived benefit refers to the individual's expectation of the potential for a positive outcome during or from an online transaction. When an individual trusts a website, it tends to increase the level of the individual's perception of benefits gained from the website. The relationship between trust and benefit in e-commerce was tested by Kim et al. [20] and supported the hypothesis that an individual's trust is positively related to their perceived benefit.

In terms of the relationship between perceived benefits and willingness to purchase, we expect that the anticipation of the benefits the individual stands to gain (e.g. usefulness, productivity) provides some basis for its positive influence on willingness to purchase. Therefore, we hypothesize that:

H4. Perceived benefit (BENEFIT) is positively related to a consumer's trust (TRUST).
H5. Perceived benefit (BENEFIT) is positively related to a consumer's WP

For control variables, consumer disposition to trust (DT) refers to a customer's general propensity to trust others, which can also influence an individual's beliefs and intentions toward e-vendors [24,29]. Since consumers have different developmental experiences, personality types, and cultural backgrounds, they differ in their inherent trust propensity. This individual trait is not based upon experience with or knowledge of a specific trusted party but is the result of ongoing lifelong experience and socialization $[9,30,38]$. Thus, we expect that if consumers have a high disposition to trust others in general, they are more likely to have a higher degree of trust in the e-vendor and a lower risk perception than if they have a low disposition to trust others in general.

Although the dollar value ${ }^{1}$ of a purchase is not a matter of primary theoretical interest in this paper, we include the variable in our model to recognize the effect of dollar cost on the key constructs including consumers' risk perception and trust. It is generally expected that when consumers purchase more expensive products or services, they are more risk sensitive and/or trust sensitive [1]. Thus, we expect that if consumers purchase more expensive products or services, they are more likely to perceive higher risk and lower trust in the e-vendor.

In contrast to a consumer's disposition to trust, a consumer's familiarity with an e-vendor is based on knowledge and/or previous experience with the evendor [19]. A consumer's familiarity with an evendor refers to the degree that the consumer is acquainted with the e-vendor, which includes knowledge of the vendor and understanding its relevant procedures such as searching for products and information and ordering through the Website's purchasing interface. Familiarity is a "precondition or prerequisite of trust" [25]. This is because it provides an understanding of the trustor's current actions which can be used to develop more. accurate and confident expectations about a trustor's future behaviors, in this case the likelihood that a trustor will fulfill its future obligations (i.e., be worthy of trust) [10]. Therefore, we expect that familiarity with an e-vendor will affect key constructs.

\section{Methodology}

This study empirically assesses the impact of the limitation of data collection and hypotheses

\footnotetext{
1 The dollar value was measured using the question, "how much would you spend for this transaction?"
} 
confirmation on the effectiveness of trust as a determinant for e-commerce transactions. We compare the results of testing both high and low trust on willingness to purchase in e-commerce without these limitations.

\subsection{Measures}

All the research constructs of interest are adopted from Kim et al. [20]; the measurement scales are the same as were used in the earlier research. Key constructs were measured using a minimum of three items on a 7-point Likert scale. Perceived risk and benefits were operationalized as formative, while willingness to purchase and trust were operationalized as reflective. In addition, we compared all constructs of the study in terms of the key concept used in definition, time frame, types of indicators, and theories used. Table 1 shows the comparison.

\begin{tabular}{|l|l|l|l|}
\hline Constructs & $\begin{array}{l}\text { Key concept } \\
\text { in definition }\end{array}$ & $\begin{array}{c}\text { Types of } \\
\text { Indicators }\end{array}$ & $\begin{array}{l}\text { Theory construct } \\
\text { derived from }\end{array}$ \\
\hline $\begin{array}{l}\text { Consumer } \\
\text { Trust } \\
\text { (TRUST) }\end{array}$ & $\begin{array}{l}\text { Subjective } \\
\text { belief }\end{array}$ & Reflective & $\begin{array}{l}\text { A multi- } \\
\text { dimensional } \\
\text { concept of trust } \\
{[36]}\end{array}$ \\
\hline $\begin{array}{l}\text { Perceived } \\
\text { Risk } \\
\text { (RISK) }\end{array}$ & Perception & Formative & $\begin{array}{l}\text { Valence } \\
\text { Framework }\end{array}$ \\
\hline $\begin{array}{l}\text { Perceived } \\
\text { Benefit } \\
\text { (BENEFIT) }\end{array}$ & Perception & Formative & $\begin{array}{l}\text { Valence } \\
\text { Framework }\end{array}$ \\
\hline WP & Willingness & Reflective & $\begin{array}{l}\text { Theory of } \\
\text { Reasoned Action }\end{array}$ \\
\hline
\end{tabular}

Table 1: Comparison of Key Constructs

In this study we handle the indicators for perceived benefit and perceived risk as a formative way. In many instances, choosing between a reflective and a formative indicator may not be an easy task because the directionality of the relationship is not always straightforward. When indicators could be viewed as causing rather than being caused by the latent variable measured by the indictors, the indicators are operationalized by formative means [27]. For example, socio-economic status is typically conceived as combinations of education, income and occupation, and their indicators should be formative. Likewise, perceived benefit, perceived risk, and perceived performance constructs of this study can be measured as combinations of different types of risk, benefit, and performance measures respectively, so that the direction of causality is from indicator to construct (i.e., formative).

In sum, we believe our procedures have ensured that the constructs and their operationalizations are consistent with prior literature, are conceptually distinct, are reliable, and have adequate face, convergent, and discriminant validity.

\subsection{Research Design and Data Collection Procedure}

Most studies in the e-commerce environment have collected data concerning a consumer's successful purchasing experiences. Yet, since successful cases represent only a fraction of all consumer transaction behaviors, these studies may have given an incomplete picture (i.e., biased view) of B2C electronic commerce transactions. Therefore, in this study, we developed a research design to overcome this bias by examining balanced transaction experiences through balanced data collection strategies (i.e. more inclined and less inclined cases). In other words, we collected data from "successful" cases where the respondents were more inclined to purchase as well as "unsuccessful" cases where they were less inclined to purchase. Through this research design and data collection procedure, we attempt to provide a more complete picture (i.e., balanced view) that explains the reasons for purchases as well as non-purchases.

The data was collected from students who participated in the study voluntarily for extra credit. In order to motivate the students to make serious purchases, we conducted this field survey in one of the first few weeks of the semester because the early part of the semester is when students typically need many items (e.g., book, clothes, CDs, software, computers). They were also requested to report what, when and where they made their purchases as well as their payment method. The detailed data collection procedures are as follows. First, participants were asked to visit at least two e-commerce websites of their choosing to shop for an item of their choice based on their comparison. Second, to ensure that the data had adequate balance in "more inclined" vs. "less inclined" cases, respondents were randomly assigned to complete one of two questionnaires: one questionnaire (QUES MORE INCLINED) asked about prepurchase constructs of the research (i.e., TRUST, RISK, BENEFIT, WP and Disposition to Trust, Familiarity, and Dollar value) about the site from which the respondent was more inclined to make a purchase; the other questionnaire (QUES_LESS_INCLINED) asked the same questions, but about the site from which the respondent was less inclined to make a purchase. This procedure ensured that, across the sample, we collected data that were likely to predict "successful" cases as well as "unsuccessful" cases. If we had failed to do this, the 
WP of the study would have consisted almost entirely of purchase cases.

The elimination of invalid responses resulted in 469 useable samples, with 261 identified as more-inclined responses, and 208 as less-inclined responses. Demographic details of the 469 respondents include 57.8 percent male and 42.2 percent female; 73.5 percent had some college, while 14.1 finished high school and the rest recorded post graduate as their highest level of education completed. Table 2 provides the characteristics of the respondents.

\begin{tabular}{|c|c|c|}
\hline Characteristics & $\begin{array}{l}\text { More inclined } \\
\text { to purchase } \\
(n=261)\end{array}$ & $\begin{array}{c}\text { Less } \\
\text { inclined to } \\
\text { purchase } \\
(\mathbf{n}=\mathbf{2 0 8})\end{array}$ \\
\hline Age & $21.07(2.36)^{+}$ & $21.87(2.21)^{+}$ \\
\hline $\begin{array}{l}\text { Gender (Frequency; } \\
\text { Percent) } \\
\text { Male } \\
\text { Female }\end{array}$ & $\begin{array}{l}149 ; 57.8 \\
109 ; 42.2\end{array}$ & $\begin{array}{c}112 ; 56.3 \\
87 ; 43.7\end{array}$ \\
\hline $\begin{array}{l}\text { Hours per day on the } \\
\text { web (web searching, } \\
\text { browsing, e-mail } \\
\text { checking, chatting, etc.) }\end{array}$ & $2.50(1.29)$ & $2.80(3.8)$ \\
\hline $\begin{array}{l}\text { Hours per day on } \\
\text { computer (including } \\
\text { spending on the web) }\end{array}$ & $3.14(1.41)$ & $3.54(2.6)$ \\
\hline $\begin{array}{l}\text { Self-rating on computer } \\
\text { skill (1-Novice / 7- } \\
\text { Expert) }\end{array}$ & $5.31(1.04)$ & $4.06(1.23)$ \\
\hline $\begin{array}{l}\text { Self-rating on the } \\
\text { Internet skill (e.g., } \\
\text { searching, browsing, } \\
\text { finding information, etc.) } \\
\text { (1-Novice / 7-Expert) }\end{array}$ & $5.52(0.99)$ & $4.66(1.65)$ \\
\hline
\end{tabular}

Note: + - Mean (S.D.): standard deviation

Table 2: Characteristics of Respondents

\section{Data Analysis and Results}

\section{1. Testing the measurement model}

Partial least squares (PLS) was used in this study for measurement validation and structural model testing. SmartPLS 2.0 was used because it allows for the modeling of latent constructs as formative or reflective indicators. PLS is appropriate for this study because it allows for latent constructs to be modeled with formative and reflective indicators at the same time [17]. In addition, PLS places minimal restrictions on sample size and residual distribution [6]. The measurement model was tested based on the adequacy of these criteria; reliability, convergent validity and discriminant validity. Table 3 shows the results of all criteria evaluations for both the purchase and nonpurchase cases. Reliability was evaluated based on
Cronbach Alpha, and all values are above 0.7 . Convergent validity was assessed by examining average variance extracted (AVE); it ranged from .67 to 0.89 , well above the recommend values of 0.5 , thus showing convergent reliability. As a stronger test of discriminant validity suggested by Fornell and Lacker [8], the average variance extracted (AVE) can also be used: the AVE for the construct should be higher than the variance shared between the construct and other constructs in the model. Shown in Table 3, in all cases the correlations between each pair of constructs were lower than the square root of the AVE for the relevant constructs. Therefore, these test results confirm that all the constructs are empirically distinct. Note that the evaluation for RISK and BENEFIT were not applicable as these are modeled as formative constructs.

\begin{tabular}{|c|c|c|c|c|c|c|c|c|c|}
\hline Constructs & Alpha & CR & AVE & 1 & 2 & 3 & 4 & 5 & 6 \\
\hline \multicolumn{10}{|c|}{ (Case 1: more inclined to purchase) } \\
\hline 1. TRUST & 0.865 & 0.918 & 0.788 & 0.888 & & & & & \\
\hline 2. RISK & NA & NA & NA & -0.503 & NA & & & & \\
\hline 3. BENEFIT & NA & NA & NA & 0.537 & -0.497 & NA & & & \\
\hline 4. WP & 0.824 & 0.895 & 0.740 & 0.717 & -0.532 & 0.616 & 0.860 & & \\
\hline 5. DT & 0.852 & 0.898 & 0.688 & 0.189 & -0.136 & 0.043 & 0.181 & 0.830 & \\
\hline 6. FAM & 0.963 & 0.973 & 0.899 & 0.368 & -0.302 & 0.369 & 0.412 & -0.002 & 0.948 \\
\hline \multicolumn{10}{|c|}{ (Case 2: less inclined to purchase) } \\
\hline Constructs & Alpha & $\mathrm{CR}$ & AVE & 1 & 2 & 3 & 4 & 5 & 6 \\
\hline 1. TRUST & 0.833 & 0.900 & 0.751 & 0.866 & & & & & \\
\hline 2. RISK & NA & NA & NA & -0.424 & NA & & & & \\
\hline 3. BENEFIT & NA & NA & NA & 0.428 & -0.379 & NA & & & \\
\hline 4. WP & 0.757 & 0.860 & 0.672 & 0.304 & -0.406 & 0.471 & 0.820 & & \\
\hline 5. DT & 0.850 & 0.889 & 0.667 & 0.331 & -0.179 & 0.171 & 0.102 & 0.816 & \\
\hline 6. FAM & 0.924 & 0.946 & 0.815 & 0.288 & -0.210 & 0.507 & 0.287 & 0.158 & 0.903 \\
\hline
\end{tabular}

Note: CR: Composite Reliability, AVE: Average Variance Extracted, Diagonal elements are the square root of AVE. These values should exceed the off-diagonal inter-construct correlations for adequate discriminant validity.

Table 3. Reliability, Correlation, and Discriminant Validity of Constructs

\subsection{Testing the Structural Model and Model Comparison}

Results of the structural model testing are presented in Figure 3. Bootstrapping analysis was performed to test the structural model [5]. The two models in Figure 3 are the case 1 (more inclined to purchase) and case 2 (less inclined to purchase). It also shows that all path coefficients of the hypothesized causal links from the 
Valence Framework [35] (i.e., RISK $\rightarrow$ WP and BENEFIT $\rightarrow$ WP) are significant $(p<.001)$ for both cases.

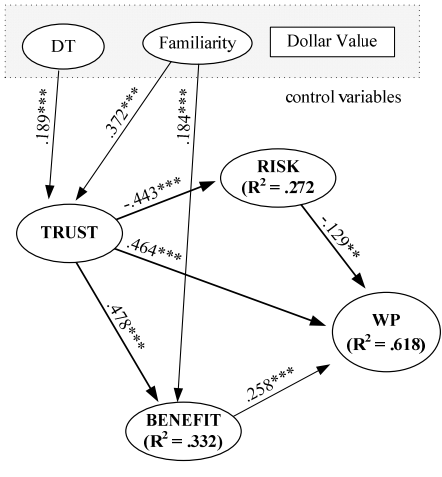

Model la (casel: more inclined to purchase)

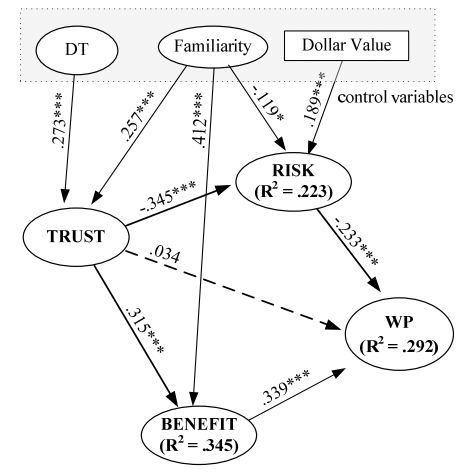

Model 1b (case 2: less inclined to purchase)
Note: ${ }^{*}$ Significant at the $0.05,{ }^{* *}$ significant at the $0.01,{ }^{* * *}$ significant at the 0.001 level

Figure 3: Results of Structure Models and Comparison

A very interesting finding follows. In model 1a (i.e. model showing the more inclined purchasers), all hypothesized paths are significant. TRUST $(\beta=.464$, $\mathrm{p}<0.001$ ) is the most significant determinant of WP, supporting hypothesis 1A. As expected, TRUST has a significant negative effect on RISK $(\beta=-.443, p<0.01)$ and significant positive effect on BENEFIT $(\beta=.478$, $\mathrm{p}<0.01)$. Therefore, hypotheses 2 and 3 are supported. RISK $(\beta=-.129, \mathrm{p}<0.01)$ and BENEFIT $(\beta=.258$, $\mathrm{p}<0.001$ ) are also significant determinants of WP, thus supporting hypotheses 4 and 5 . Trust as a predictor of risk accounted for 27 percent of the variance in RISK, and 33 percent of the variance in BENEFIT. Together these predictors explained more than 60 percent of the variance in WP. However, in model 1b (i.e. model showing the less inclined to make a purchase), a test of all hypothesized paths for the group that were less inclined to purchase shows significant, except the relationship between TRUST and WP, which represents hypothesis $1 \mathrm{~b}$. The effect of TRUST on WP $(\beta=-.034)$ is not significant, which though it supports the hypothesis that said there will be a weak positive effect of trust (TRUST) on a consumer's WP when there is low levels of consumer trust, is reported as statistically not significant. Hence, low TRUST is not a significant determinant of WP. Also in this model, though the paths are slightly lower than in model 1, they are nevertheless significant. TRUST is found to have a significant negative relationship to RISK ( $\beta=$ $.345, \mathrm{p}<0.001)$ and significant positive effect on BENEFIT $(\beta=.315, \mathrm{p}<0.001)$, supporting hypotheses 2 and 3. RISK $(\beta=-.233, p<0.001)$ negatively affected WP, and BENEFIT $(\beta=.339, \mathrm{p}<0.001)$ positively affected WP, supporting hypotheses 4 and 5 . Together WP, BENEFIT and RISK explains 29 percent of the variance in WP for the model testing of the lessinclined to purchase group.

In the case of familiarity, disposition to trust and dollar value, Model 1a and Model 1b similarly indicated significant determinants of trust. In model $1 \mathrm{a}$, DT $(\beta=.189, \mathrm{p}<0.001)$ and FAM $(\beta=.372$, $\mathrm{p}<0.001)$ have a significant effect on TRUST. FAM $(\beta$ $=.184, \mathrm{p}<0.001)$ also has a significant effect on BENEFIT. Dollar value does not have a significant effect on the any of the predictors. In model $1 b$, DT $(\beta$ $=.273, \mathrm{p}<0.001)$ and FAM $(\beta=.257, \mathrm{p}<0.001)$ have a significant effect on TRUST. FAM also has a significant positive effect on BENEFIT $(\beta=.412$, $\mathrm{p}<0.001)$, and negative effect on RISK $(\beta=-.119$, $\mathrm{p}<0.05)$. Dollar value has a significant effect on RISK $(\beta=.189, \mathrm{p}<0.001)$.

\section{Discussion and Conclusion}

There are theoretical and practical implications of the study. From a theoretical point of view, this research identifies a bias of confirmatory aspect of investigation with successful cases (e.g., successful purchase experiences or more inclined to purchase cases). To minimize the bias, the research suggests a strategy to collect a balanced data for testing the critical role of trust in e-commerce transactions. This strategy may apply to other empirical studies in testing the main effect of a focal construct in proposed research models. For example, in studying the effect of privacy concern as the critical factor in willingness to disclose information, researchers may, in order to validate and assert that privacy concern is really the major determinant, take a balanced data collection approach. An approach to collect data geared towards "willingness to disclose information" as well as data geared towards "unwillingness to disclose information"; a comparison model. The result of the test using both data sets and comparison model should clearly show the relationship between privacy concern and "unwillingness to disclose information" as not significant. Otherwise, other factors within the test could be seen as focal determinants. Therefore, in other to say that any focal construct is the major determinant, one should test both sides and compare the models with results clearly showing the varying effect of the focal construct under the tested conditions.

The field of psychology has since noted that human reasoning is subject to positive confirmation, and as a result there is a tendency to test existing beliefs for evidence that only confirms that belief [18]. The proposed approach utilized in this study is one that 
uses both successful and unsuccessful case data in testing, an important approach for the evaluation of the validity of a belief. Indeed, the use of only confirmation tests has been successful in predicting and explaining the effects of high levels of trust on intention in e-commerce - i.e., a biased case of empirical situation with higher level of trust. However, it should be complemented with a balanced method that involves collecting empirical data in order to fully validate and understand the effect of trust in ecommerce. In the current research, we planned a careful research design and data collection that allowed for demarcation such that the dependent variable could predict less inclined to purchase as well as more inclined to purchase, and then we tested the effect of trust as a focal construct of the proposed research model for both cases. Having tested both situations in this study, the contrast results provide a clear assertion that trust is the key determinant of willingness to purchase in e-commerce transactions. Without testing both sides, we paint a simple but incomplete picture.

In most previous studies that evaluate the effect of trust, the results show that high trust affects intention (i.e. willingness to purchase), but if on some occasions low trust also positively affects intention, could one reasonably assert that trust is the critical factor affecting intention, without testing for both cases of more inclined to purchase and less inclined to purchase?

From a practical perspective, this research provides implications. First, as the influence of trust increases and spans many domains in information systems, (e.g. m-commerce, information security, project implementation etc.) it is important that more rigor is applied in testing its effects under various conditions. The application of such rigor adds to the confidence practitioners have in the application and enhancement of trusting conditions. Such confidence provides practitioners a clearer indication of how and when to add or remove resources as they pursue and maintain client trust in the online marketplace. In the current study, it is less about suggesting that trust studies have traditionally tested for cases that have the best chance of verifying current beliefs [23], rather it is suggesting that a balanced analysis be performed in order to fully understand and explain the nature and concept of trust in e-commerce. Given the vast amount of studies testing the impact of trust on e-commerce and resulting in both statistical and practical significance, trust is viewed as a strong enough construct and concept. Hence, we propose the testing of hypotheses for both successful and unsuccessful, in part because doing so provides a more balanced and a less biased evidence of the impact of trust in e-commerce. Otherwise its power is incompletely tested, and we are left to wonder other ways to harness its potential in e-commerce, mcommerce, and in the authentication methods that allow 'm-e-commerce' (mobile-electronic-commerce) to flourish.

\subsection{Limitations and Suggestions for Future Directions}

First, given that this is a single study, we caution the conclusions drawn from the study. Examining the strength and varying effect of a focal construct in a study may require several replications of the study. Second, although this study focuses more on data collection and testing methodology and less on the sample, nevertheless, data was collected using students and presents a possible limitation of this study. Therefore, this study may need to be replicated with other samples because our empirical results may not generalize to other online populations, or to cultures outside the United States. Third, in order to maintain consistency with the literature, the measurement items in this study were selected from Kim et al. [20] with the intent to replicate their measurement items. The reason for the design choice is so as to prevent the introduction of alternate explanations, but rather promote the balanced data collection and testing methodology ideas proposed in this research. Hence, any measurement limitations of Kim et al. [20] will apply to this study.

In conclusion, this study stresses the need for an unbiased investigation of the impact of trust in online transactions in IS research, in order to fully understand the complex effect of trust on transaction activity. Thus, offering new perspectives on data collection and testing of the effects of trust on decision making. The approach not only provides a more balanced view of the critical role of trust in e-commerce transaction decisions, but it also enhances the rigor in measuring and testing of social behaviors in IS discipline that seeks conditions that forbid certain things from occurring [37], or accounts for conditions of normal and non-normal performance [21]. This research seeks to encourage dialogue beneficial for future empirical studies handling focal constructs.

\section{References}

[1] Ba, S. and Pavlou, P. Evidence of the effect of trust building technology in electronic markets: Price premiums and buyer behavior. MIS Quarterly, 26, 3 (2002), 243-268.

[2] Bhattacherjee, A. Understanding Information Systems Continuance: An Expectation-Confirmation Model. MIS Quarterly, 25, 3 (2001), 351-370.

[3] Bhattacherjee, A. Individual trust in online firms: 
Scale development and initial test. Journal of Management Information Systems, 19, 1 (2002), 211-241.

[4] Bhattacherjee, A. and Premkumar, G.

Understanding changes in belief and attitude toward information technology usage: A theoretical model and longitudinal test. MIS Quarterly, 28, 4 (2004), 229-254.

[5] Chin, W.W. Issues and Opinion on Structural Equation Modeling. MIS Quarterly, 22, 1 (1998), vii-xvi.

[6] Chin, W.W. and Newsted, P.R. Structural equation modeling analysis with small samples using partial least squares. (1999).

[7] Dabholkar, P., Shepherd, D., and Thorpe, D. A comprehensive framework for service quality: an investigation of critical conceptual and measurement issues through a longitudinal study. Journal of Retailing, 76, 2 (2000), 139-173.

[8] Fornell, C. and Larcker, D.F. Structural equation models with unobservable variables and measurement error: Algebra and statistics. Journal of marketing research, (1981), 382-388.

[9] Fukuyama, F. Trust: The social virtues and the creation of prosperity. Free Press, New York, 1995.

[10] Gefen, D. E-commerce: the role of familiarity and trust. Omega, 28, 6 (2000), 725-737.

[11] Gefen, D., Benbasat, I., and Pavlou, P. A research agenda for trust in online environments. Journal of Management Information Systems, 24, 4 (2008), 275-286.

[12] Gefen, D., Karahanna, E., and Straub, D.W. Trust and TAM in online shopping: an integrated model. MIS Quarterly, 27, 1 (2003), 51-90.

[13] Gefen, D., Rose, G., Warkentin, M., and Pavlou, P. Cultural diversity and trust in IT adoption: A comparison of potential e-voters in the USA and South Africa. Journal of Global Information Management, 13, 1 (2005).

[14] Gefen, D. and Straub, D.W. Managing user trust in B2C e-services. e-Service Journal, 2, 2 (2003), 724.

[15] Glover, S. and Benbasat, I. A comprehensive model of perceived risk of e-commerce transactions. International Journal of Electronic Commerce, 15, 2 (2010), 47-78.

[16] Goodwin, N. Economic meanings of trust and responsibility. The University of Michigan Press, Ann Arbor, MI, 1996.

[17] Hair, J.F.J., Hult, G.T.M., Ringle, C.M., and Sarstedt, M. A Primer on Partial Least Squares Structural Equation Modeling (PLS-SEM). Sage Publications, Inc., Thousand Oaks, CA, 2014.

[18] Jones, M. and Sugden, R. Positive confirmation bias in the acquisition of information. Theory and Decision, 50, 1 (2001), 59-99.

[19] Kim, D.J., Ferrin, D.L., and Rao, H.R. A trust-based consumer decision-making model in electronic commerce: The role of trust, perceived risk, and their antecedents. Decision Support Systems, 44, 2 (2008), 544-564.
[20] Kim, D.J., Ferrin, D.L., and Rao, H.R. Trust and satisfaction, two stepping stones for successful ecommerce relationships: A longitudinal exploration. Information Systems Research, 20, 2 (2009), 237257.

[21] Klahr, D. and Simon, H.A. Studies of scientific discovery: Complementary approaches and convergent findings. Psychological Bulletin, 125, 5 (1999), 524.

[22] Klayman, J. Varieties of confirmation bias. Psychology of learning and motivation, 32, (1995), 385-418.

[23] Klayman, J. and Ha, Y.-W. Confirmation, disconfirmation, and information in hypothesis testing. Psychological review, 94, 2 (1987), 211.

[24] Kristensen, K., Martensen, A., and Gronholdt, L. Measuring the impact of buying behaviour on customer satisfaction. Total Quality Management, 10, 4-5 (July 1999), 602-614.

[25] Luhmann, N. Trust and power. John Wiley and Sons, Inc, United Kingdom, 1979.

[26] Luhmann, N. Familiarity, confidence, trust: Problems and alternatives. Trust: Making and breaking cooperative relations, 6, (2000), 94-107.

[27] MacCallum, R. and Brown, M. The use of causal indicators in covariance structure models: Some practical issues. Psychological bulletin, 114, 3 (1993), 533.

[28] Mayer, R.C., Davis, J.H., and Schoorman, F.D. An integrative model of organizational trust. Academy of Management Review, 20, 3 (1995), 709-734.

[29] McKnight, D.H., Choudhury, V., and Kacmar, C. Developing and validating trust measures for ecommerce: an integrative typology. Information Systems Research, 13, 3 (2002), 334-359.

[30] McKnight, D.H., Cummings, L.L., and Chervany, N.L. Initial trust formation in new organizational relationships. Academy of Management Review, 23, 3 (1998), 473-490.

[31] Nicolaou, A.I. and McKnight, D.H. Perceived Information Quality in Data Exchanges: Effects on Risk, Trust, and Intention to Use. Information Systems Research, 17, 4 (2006), 332-351.

[32] Oliver, R.L. and Burke, R.R. Expectation Processes in Satisfaction Formation. Journal of Service Research, 1, 3 (February 1999), 196-214.

[33] Patterson, P., Johnson, L., and Spreng, R. Modeling the Determinants of Customer Satisfaction for Business-to-Business Professional Services. Journal of the Academy of Marketing Science, 25, 1 (December 1996), 4-17.

[34] Pavlou, P.A. Consumer acceptance of electronic commerce: Integrating trust and risk with the technology acceptance model. International Journal of Electronic Commerce, 7, 3 (2003), 101-134.

[35] Peter, J.P. and Tarpey, L.X. A comparative analysis of three consumer decision strategies. Journal of Consumer Research, (1975), 29-37.

[36] Plank, R., Reid, D., and Pullins, E. Perceived Trust in Business-to-Business Sales: A New Measure. Journal of personal selling \& sales management, 
19, 3 (1999), 61-71.

[37] Popper, K. Conjectures and refutations: The growth of scientific knowledge. Routledge, London, UK, 1969.

[38] Rotter, J. Generalized expectancies for interpersonal trust. American Psychologist, 26, 5 (1971), 443450.

[39] Snyder, M. and Swann, W.B. Hypothesis-testing processes in social interaction. Journal of Personality and Social Psychology, 36, 11 (1978), 1202.

[40] Spreng, R.A., MacKenzie, S.B., and Olshavsky, R.W. A Reexamination of the Determinants of Consumer Satisfaction. Journal of Marketing, 60, 3
(July 1996), 15-32.

[41] Swan, J. and Trawick, F. Disconfirmation of expectations and satisfaction with a retail service. Journal of Retailing, 57, 3 (1981), 49-67.

[42] Tesch, D., Jiang, J.J., and Klein, G. The Impact of Information System Personnel Skill Discrepancies on Stakeholder Satisfaction. Decision Sciences, 34, 1 (February 2003), 107-129.

[43] Urban, G. and Sultan, F. Placing trust at the center of your Internet strategy. Sloan Management Review, 42, 1 (2000), 39-48. 